\title{
Epidemiology of sage downy mildew, Peronospora salviae-officinalis
}

\author{
M. Hoffmeister (D) - D. Gabriel (D) - M. Thines (D) • \\ W. Maier (D)
}

Accepted: 26 February 2020 /Published online: 4 April 2020

(C) The Author(s) 2020

\begin{abstract}
Downy mildew of common sage (Salvia officinalis), caused by Peronospora salviae-officinalis, has become a serious problem in sage production worldwide. The effect of temperature was determined for conidia germination and disease development. In vitro, conidial germination rate was highest at temperatures between $10^{\circ} \mathrm{C}$ and $20^{\circ} \mathrm{C}$ and was strongly reduced at temperatures above 25 , but conidia were also able to germinate at $2{ }^{\circ} \mathrm{C}$. Temperatures between 15 and $20{ }^{\circ} \mathrm{C}$ were most favourable for infection and disease progress in infection experiments in climate chambers, with
\end{abstract}

Electronic supplementary material The online version of this article (https://doi.org/10.1007/s10658-020-01967-1) contains supplementary material, which is available to authorized users.

M. Hoffmeister $(\square) \cdot$ W. Maier $(\square)$

Institute for Epidemiology and Pathogen Diagnostics, Julius Kühn-Institut (JKI) - Federal Research Centre for Cultivated Plants, Messeweg 11/12, 38104 Braunschweig, Germany e-mail: mascha.hoffmeister@julius-kuehn.de

e-mail: wolfgang.maier@julius-kuehn.de

D. Gabriel

Institute for Crop and Soil Science, Julius Kühn-Institut (JKI) - Federal Research Centre for Cultivated Plants, Braunschweig, Germany

M. Thines

Faculty of Biological Sciences, Institute of Ecology, Evolution and Diversity, Goethe University, Max-von-Laue-Str. 13,

D-60438 Frankfurt am Main, Germany

M. Thines

Senckenberg Biodiversity and Climate Research Centre, Senckenberganlage 25, D-60325 Frankfurt am Main, Germany highest sporulating leaf area observed at 15 and $20^{\circ} \mathrm{C}$, and highest symptomatic leaf area at $20^{\circ} \mathrm{C}$. P. salviaeofficinalis is still able to infect sage plants at $5{ }^{\circ} \mathrm{C}$, but sporulation was only observed at higher temperatures. Oospores developed 14 days after inoculation at $15^{\circ} \mathrm{C}$, and 8 days after inoculation at 20 and $25{ }^{\circ} \mathrm{C}$. The infection trials also showed that dark incubation is not a prerequisite for successful infection of sage. Furthermore, $P$. salviae-officinalis needs two events of leaf wetness or high humidity to complete its asexual life cycle. First, a leaf wetness event of at least three hours is needed for conidial germination and penetration of the host. Second, high humidity of at least $90 \%$ is needed at the end of the infection cycle for sporulation. Seed washing revealed the presence of $P$. salviae-officinalis oospores in seed lots of sage suggesting that infested seeds might play a major role in the fast spread of sage downy mildew, which is an important finding for phytosanitary or quarantine measures.

Keywords Downy mildew. Infection studies · Peronospora salviae-officinalis · Oospores · Salvia officinalis $\cdot$ Seed testing

\section{Introduction}

Common sage, Salvia officinalis (Lamiaceae), is the economically most important sage species (Raal et al. 2007; Mirjalili et al. 2006) and has been used as a medicinal plant since ancient times due to its antimicrobial activities (Longaray Delamare et al. 2007). 
Furthermore, these aromatic plants are used as culinary herbs and flavouring agents, and for perfumery and cosmetics (Sulniute et al. 2017).

Over the past two decades several downy mildew diseases in medicinal and spice plants have been newly reported and led to economic losses, for example Peronospora somniferi on opium poppy (Papaver somniferum) (Voglmayr et al. 2014), P. belbahrii on basil (Ocimum basilicum) (Thines et al. 2009), and P. salviaeofficinalis on common sage (Choi et al. 2009). To our knowledge the downy mildew on $S$. officinalis has been officially reported for the first time in Florida in 1993, but had been initially attributed to P. lamii (McMillan 1993). Earlier reports of downy mildews on sage species mention the occurrence of $P$. lamii and $P$. swinglei on $S$. pratensis (meadow sage), S. lanceolata (lance-leaf sage) or $S$. sclarea (clary sage) but not on $S$. officinalis (Rabenhorst 1857; Ellis and Kellerman 1887; Gäumann 1923; Kochman 1970; USDA 1960; Osipjan 1967; Stanjavičenie 1984). In the meantime, downy mildew on common sage has been reported from Israel, Austria, Italy, New Zeeland, Australia, UK and Germany (Gamliel and Yarden 1998; Plenk 2002; Hill et al. 2004; Belbahri et al. 2005; Liberato et al. 2006; HumphreysJones et al. 2008; Choi et al. 2009).

Despite the fact that $P$. salviae-officinalis was described a decade ago (Choi et al. 2009) very little is known about its infection biology and epidemiology. This knowledge is, however, crucial for targeted and efficient pest management strategies against downy mildew in sage production as well as for the development of forecast models. It is also still unclear how the disease was able to spread throughout the world so quickly. It was hypothesized that downy mildew on S. officinalis might has been distributed by contaminated seed lots (Choi et al. 2009), but proof for this hypothesis is still lacking and oospores, which could play an important role in the spread of the disease, have been reported only on sage leaves (Plenk 2002; Liberato et al. 2006; Humphreys-Jones et al. 2008).

The objectives of the present study were to examine the epidemiological parameters for successful infection of sage by P. salviae-officinalis. The effect of temperature on conidia germination was determined in vitro. The effect of temperature and leaf wetness on infection and disease development was evaluated in climate chamber experiments in vivo. Furthermore, we screened for oospores during the infection trials to evaluate whether and how frequently this long-lasting inoculum source is produced. We also examined seed lots of sage for downy mildew contamination using a seed washing method in combination with light microscopy, as well as PCR-based detection, to determine if the pathogen is present in traded seed lots.

\section{Material and methods}

Inoculum production and inoculation

Infection experiments were carried out using a P. salviae-officinalis population isolated from a common sage stand in Saxony (Germany). The downy mildew was cultivated and reproduced on $S$. officinalis under controlled conditions as described below. To ensure that the plants were healthy before inoculation, sterile-grown in vitro plants (Elsner pac Vertriebsgesellschaft mbH, Dresden, Germany) were used. After delivery, the plants were transferred from the cups with culture media to multipot plates $(8 \times 12$ plots/ plate) filled with seeding compost and cultured in the greenhouse $\left(20{ }^{\circ} \mathrm{C}, 16 \mathrm{~h}\right.$ light/ $8 \mathrm{~h}$ dark, $60 \%$ humidity) under a hood for about two weeks. After root formation the hood was removed and single plants were potted into containers $(8 \mathrm{~cm}$ diameter, $190 \mathrm{ml}$, Pöppelmann GmbH \& Co. KG., Lohne, Germany) with standard potting compost (Substrat 1, KlasmannDeilmann $\mathrm{GmbH}$, Geeste, Germany; chemical analysis [mg per $100 \mathrm{~g}$ ]: $N=140, P=100, \mathrm{~K}=180, \mathrm{Mg}=100$, $\mathrm{S}=120$; salinity $1.0 \mathrm{~g} / \mathrm{L} ; \mathrm{pH} 5.5$ ). For maintenance of P. salviae-officinalis and infection studies, inoculation using a spray bottle was conducted as soon as the plants had developed four mature leaves.

Plants were inoculated by spraying a conidial suspension $\left(1 \times 10^{4}\right.$ conidia $\left.\mathrm{ml}^{-1}\right)$ on the upper and lower leaf surface until run-off. Inoculated plants were incubated under a hood placed in a plant growth chamber (Percival Scientific, Perry, IA, U.S.A) with $15^{\circ} \mathrm{C}, 100 \%$ relative humidity (rh.) and $12 \mathrm{~h} \mathrm{light} / 12 \mathrm{~h}$ dark for 7 to 8 days until sporulation. Sage leaves with mature conidia were harvested from the plants. For infection studies only fresh inoculum was used. Conidial suspensions were prepared by rinsing off conidia with deionised water. The conidial density was calculated using a microscope (Zeiss Axioskop 2 plus compound microscope, Carl Zeiss Microscopy GmbH, Jena, Germany) and a haemocytometer (Fuchs-Rosenthal, $0.200 \mathrm{~mm}, 0.0625 \mathrm{~mm}^{2}$, Glaswarenfabrik Karl Hecht 
GmbH \& Co KG, Sondheim v. d. Rhön, Germany), and was adjusted to $10^{4}$ conidia per $\mathrm{ml}$ by dilution with deionised water. For in vitro trials $4 \mathrm{ml}$ of this conidial suspension was pipetted on the surface of $1.5 \%$ water agar in a laminar flow hood. Moist sterile filter papers were inserted into the lids of the Petri dishes to preserve high humidity within the plates and to avoid drying of the suspension. Agar plates were also sealed with parafilm (Laboratory Film, Parafilm, Bemis, North America) and incubated under the conditions specified below. For each plate, germination of 100 randomly chosen conidia was assessed microscopically using an inverted microscope (Primovert, Carl Zeiss Microscopy $\mathrm{GmbH}$, Jena, Germany). Damaged conidia or conidia without fully-developed germ tubes were not counted. In all experiments, one Petri dish represented a replicate. Sporulating and symptomatic leaf area was visually estimated by a single observer in percent with estimated values of $0,1,3,5,10$ and increments of 10 up to $100 \%$.

Evaluating the effect of the light regime and relative humidity on disease development

The effect of an initial $24 \mathrm{~h}$ incubation in darkness (24 hdark) on disease development and disease severity was compared to incubation in a natural $12 \mathrm{~h}$ day-night rhythm (12 h-d/l) starting with the day phase. Plants were incubated at $15{ }^{\circ} \mathrm{C}$ and $100 \% \mathrm{rh}$. The chlorotic and sporulating leaf areas were evaluated in percent leaf area at 7 dpi (days post inoculation) on four leaves per plant and ten plants per treatment. The experiment was repeated twice resulting in 160 observations ( 4 leaves $\times 10$ plants $\times 2$ treatments $\times 2$ replications in time).

The effect of the duration of leaf wetness directly after inoculation and relative humidity at the end of the infection cycle (5-7 dpi) on the disease development of $P$. salviae-officinalis on sage was tested. In vitro pretrials on $1.5 \%$ water agar were conducted to determine different developmental steps in the germination of conidia of $P$. salvia-officinalis during an incubation in the darkness at $15{ }^{\circ} \mathrm{C}$. In in vivo trials inoculated plants were exposed for different time spans to $60 \%$ or $100 \%$ rh. to assess the effect of the leaf wetness duration after inoculation and high humidity at the end of the infection cycle. Plants were inoculated and incubated at $15{ }^{\circ} \mathrm{C}$, $100 \% \mathrm{rh}$. and a $12 \mathrm{~h}-\mathrm{d} / \mathrm{n}$ rhythm as described above. To manipulate leaf wetness duration the hood that ensured $100 \% \mathrm{rh}$. was removed at different time points after the inoculation (3 hpi, 6 hpi, 12 hpi, 24 hpi, 48 hpi, and 5 dpi, Fig. 1) and plants were transferred to a growth chamber with $60 \% \mathrm{rh}$. These time points were inferred from the results of the preceding in vitro experiment. From the optimisation of inoculum production it was known that $P$. salviae-officinalis starts to sporulate at 5 dpi when incubated at $15{ }^{\circ} \mathrm{C}$. Hence, at the end of the infection cycle, i.e. at $5 \mathrm{dpi}$, half of the plants of each treatment were transferred again to the humid cabinet with $100 \%$ rh. and covered with a hood (Fig. 1), while the other half was kept at $60 \%$ rh. without a hood.

One control (control 1) was incubated at $60 \%$ rh. directly after the inoculation until $7 \mathrm{dpi}$. A second control (control 2) was kept under a hood in the humid cabinet from inoculation until the end of the experiment at 7 dpi. Treatment " 0 h" was kept like control 1 until 5 dpi. Then the plants were transferred to $100 \% \mathrm{rh}$. and covered with a hood until 7 dpi. Treatment " 5 dpi" was treated like the control 2 until $5 \mathrm{dpi}$, and then the plants were transferred to $60 \% \mathrm{rh}$. and the hood was removed. At 7 dpi the sporulating leaf area was evaluated in percent of total leaf area from four leaves per plant and six plants per treatment. The experiment was repeated twice, resulting in 672 observations ( 4 leaves $\times 6$ plants $\times 14$ treatments $\times 2$ replications in time).

Evaluating the effect of temperature on conidia germination in vitro and disease development in vivo

The effect of temperature on germination of freshly harvested conidia was assessed in vitro. Petri dishes with $1.5 \%$ water agar were inoculated as described above. Plates were incubated in the dark for $24 \mathrm{~h}$ and $48 \mathrm{~h}$ under the following temperatures: $2,5,10$, $15,20,25,30$ and $35^{\circ} \mathrm{C}$, respectively. Germination rates were determined microscopically. Three replicates were carried out per treatment and the experiment was conducted three times.

To assess the effect of temperature on disease development and severity in vivo an experiment was conducted taking into account the results obtained from the in vitro germination study. Sage plants were inoculated and incubated at $5,10,15,20$ and $25^{\circ} \mathrm{C}$, respectively, $12 \mathrm{~h}-\mathrm{d} / \mathrm{n}$, and $100 \% \mathrm{rh}$. in a plant growth chamber under controlled conditions as described above. The experiment was repeated three times and 16 plants (in experiments 1 and 2) and eight plants (in experiment 3), respectively, were inoculated per treatment. Sporulating leaf area and the percentage of symptomatic leaf area 

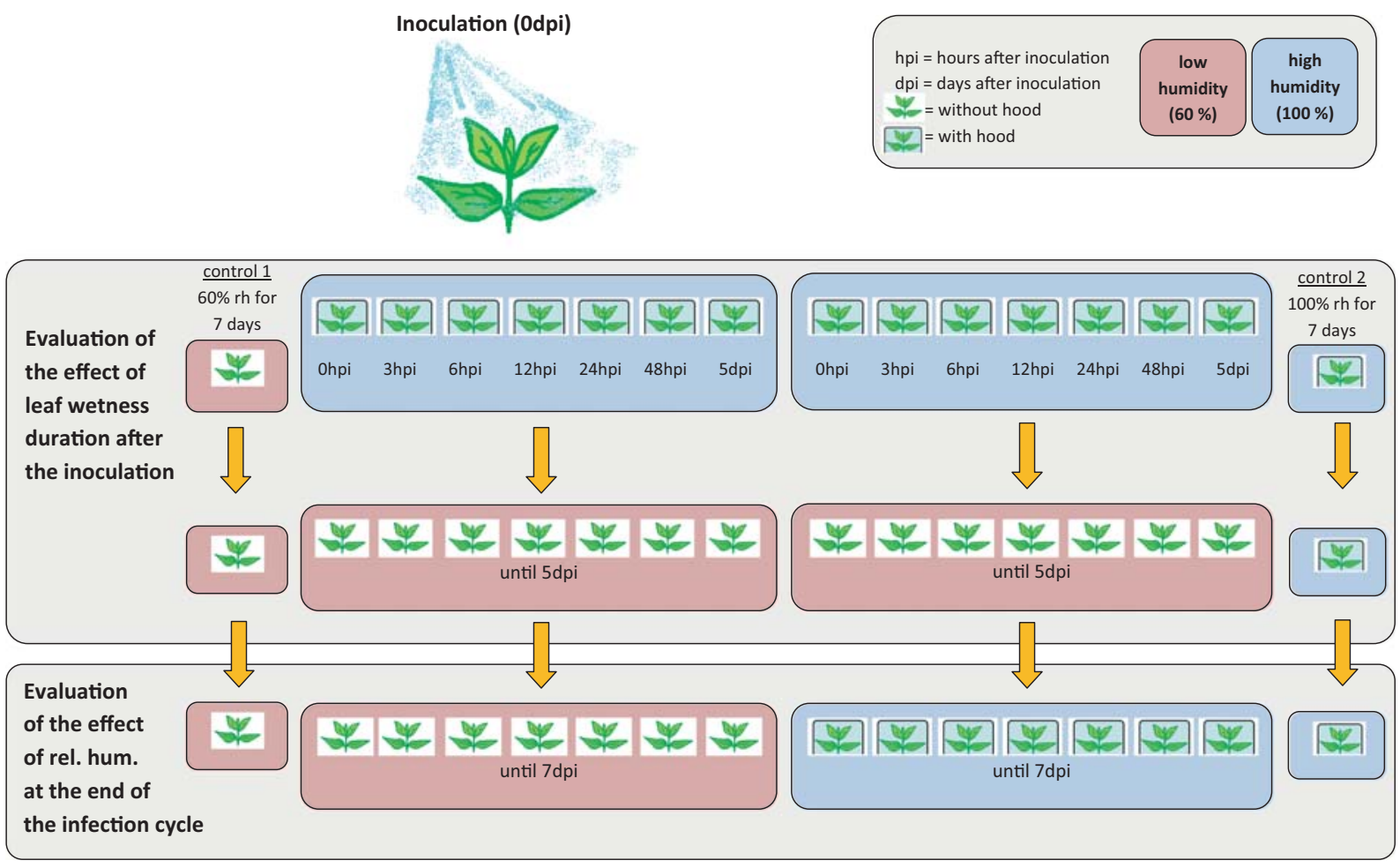

Fig. 1 Testing the effect of leaf wetness duration and relative humidity at the end of the infection cycle on disease development of Peronospora salviae-officinalis on Salvia officinalis. The

was evaluated in percent of total leaf area from four leaves per plant at 4, 5, 6, 7, 8, 9, 10 and $14 \mathrm{dpi}$.

All plants incubated at $5{ }^{\circ} \mathrm{C}$ did not show any signs of reaction to the inoculation. Hence, at 14 dpi they were transferred to $25^{\circ} \mathrm{C}$ for another three days to test whether $P$. salviae-officinalis is able to infect sage at $5{ }^{\circ} \mathrm{C}$, and to develop downy mildew once temperatures increase after the potential infection at $5{ }^{\circ} \mathrm{C}$. The treatment at $5{ }^{\circ} \mathrm{C}$ was excluded from the statistical analysis. In total 2560 observations were included in the statistical analysis ( 4 leaves $\times 16$ plants $\times 4$ treatments $\times 4$ days of observation $(8-14 \mathrm{dpi})=1024$ for experiment 1 and 2,4 leaves $\times 8$ plants $\times 4$ treatments $\times 4$ days of observation $(8-14 \mathrm{dpi})=512$ for experiment 3$)$.

\section{Seed testing for P. salviae-officinalis}

Potential contamination of sage seed lots by $P$. salviaeofficinalis was tested using eight seed samples produced by sage growers from different locations in Germany and Switzerland. This was done using both PCR-based and light microscopic detection methods, seed washing and spore filtration. For the PCR-based detection seed diagram shows the different treatments. Control 1 was incubated over the whole time of the experiment at $60 \%$ rh. Control 2 was incubated over the whole time of the experiment at $100 \% \mathrm{rh}$

samples were first visually pre-checked for conspicuousness before PCR using a stereo-microscope. Single seeds showing whitish incrustation or lesions on the surface were used for DNA isolation. Samples were transferred individually to $2.0 \mathrm{ml}$ reaction tubes and three tungsten carbide beads were added ( $3 \mathrm{~mm}$ diameter, Qiagen, Hilden, Germany). The samples were then cooled in liquid nitrogen and disrupted using a mixer mill (TissueLyser LT, Qiagen, Hilden, Germany) by shaking them twice at $50 \mathrm{~Hz}$ for 1.5 min with an intervening cooling step. Genomic DNA was extracted using the innuPREP Plant DNA Kit (Analytik Jena, Jena, Germany). ITS-PCR, specific for oomycetes, was conducted using the primers DC6 (Cooke et al. 2000) and LR-0 (Moncalvo et al. 1995). Amplification reactions were carried out in a reaction volume of $25 \mu \mathrm{l}$ containing genomic DNA, $10 \times$ Mango PCR Buffer, $0.2 \mathrm{mM}$ dNTPs, $2 \mathrm{mM} \mathrm{MgCl}{ }^{2}, 0.4 \mu \mathrm{M}$ forward and reverse primers, and 1.5 units of MangoTaq Polymerase (Bioline $\mathrm{GmbH}$, Luckenwalde, Germany). PCR conditions were as follows: an initial denaturation step of $95^{\circ} \mathrm{C}$ for $3 \mathrm{~min} ; 40$ cycles of $95^{\circ} \mathrm{C}$ for $30 \mathrm{~s}, 57^{\circ} \mathrm{C}$ for $30 \mathrm{~s}, 72{ }^{\circ} \mathrm{C}$ for $1 \mathrm{~min}$ and $30 \mathrm{~s}$, followed by a final 
extension of $72{ }^{\circ} \mathrm{C}$ for $10 \mathrm{~min}$. PCR products were separated by gel electrophoresis through a $0.8 \%$ agarose gel $(40 \mathrm{ml})$ stained with $2 \mu \mathrm{l} \mathrm{SYBR}$ safe DNA gel stain (ThermoFisher SCIENTIFIC, Dreieich, Germany) in TAE buffer. Visualization was done with UV light. PCR products were purified using the DNA Clean \& Concentrator TM-5 Kit (ZYMO RESEARCH, Freiburg, Germany). Amplicons were sequenced at Eurofins Genomics (Eurofins Genomics GmbH, Ebersberg, Germany) using the same primers that were used for PCR. Forward and reverse strands were assembled and edited using Sequencher 5.4.1 (Gene Codes Corporation, Ann Arbor, Michigan, USA). Sequences obtained in this study were deposited in GenBank under accession numbers MN308034 - MN308053.

To identify the sequences obtained from the seeds that had tested positive in PCR for oomycetous contamination phylogenetic trees were inferred in MEGA 7 (Kumar et al. 2016) using Neighbour Joining analysis (NJ) (Saitou and Nei 1987) and the Kimura 2-parameter model as substitution model. The robustness of the phylogenetic trees were assessed on the basis of 1000 bootstrap (BS) replicates (Felsenstein 1985). The data set consisted of sequences obtained from the positive PCR reactions, $P$. salviae-officinalis from infected sage leaves from this study, and several sequences of the closely-related P. belbahrii and other Peronospora species parasitic on Lamiaceae prepared by us. Also, sequences of Pythium species taken from GenBank selected according to BLASTn searches in GenBank were included in the analysis. A second NJ tree was inferred, using only the ITS sequences from $P$. salviae-officinalis and $P$. belbahrii, because of lacking resolution of these two species in the large data set.

A seed washing and spore filtration method developed for the detection of bunt (Tilletia spp.) in wheat seeds (Kietriber 1984) was used to wash-off and trap potentially adhering spores from the surface of S. officinalis seeds. For the seed washing process, $5 \mathrm{~g}$ seeds per sample were added into a $250 \mathrm{ml}$ Erlenmeyer flask with $80 \mathrm{ml}$ of detergent solution $(0.1 \%$ Tween 20 in deionised water) and were shaken for $20 \mathrm{~min}$ at $200 \mathrm{rpm}$. After shaking, the supernatant was immediately transferred to a second Erlenmeyer flask to separate it from the seeds. For filtration the supernatant was transferred into a Nalgene vacuum filtration system (MERCK, Darmstadt, Germany) with a moistened cellulose nitrate membrane filter (pore size $0.45 \mu \mathrm{m}$, diameter filter 50 mm, Sartorius AG, Göttingen, Germany).
After filtration the filter was removed with tweezers and put into a small Petri dish until microscopic evaluation. Every seed lot was washed and filtered three times. The filter device was thoroughly cleaned after each seed sample to avoid carry-over of spores. For microscopy filter papers were cut in half. Each half was transferred to a microscopy slide in a 1:1 water-glycerine mixture and covered with a cover slip. Filters were screened under a compound microscope equipped with a Jenoptik ProgRes ${ }^{\circledR}$ digital camera. Nomarski Differential Interference Contrast (DIC) was used for observing, measuring, and taking pictures of morphological structures. Images were processed using CapturePro 2.8 (Jenoptik, Jena, Germany). Conidia and oospores detected on the filter paper were picked with an insect needle after the cover slip was removed, and transferred to a microscopy slide in water for better imaging.

Statistical analyses

All statistical analyses were performed using $\mathrm{R}$ version 3.6.1 (R Core Team 2018) and various R packages. For generalized linear mixed effect models 'glmmTMB' was used (Brooks et al. 2017), 'effects' for displaying the effects from a fitted model (Fox 2019), and 'emmeans' for computing estimated marginal means (EMMs) and performing post hoc tests (Lenth 2019). Package 'dplyr' (Wickham et al. 2019) was used for data management and summary statistics. For graphics 'ggplot2' (Wickham 2016), 'ggfortify' (Tang et al. 2016) and 'gridExtra' (Auguie 2017), 'magrittr' (Bache 2014) and 'ggpubr' (Kassambara 2019) were used.

Data were analyzed using generalized linear mixed effect models, which model different probability distributions for the response, and estimate fixed and random effects. Disease development (sporulating leaf area (\%)) and disease severity (symptomatic leaf area (\%)) are both continuous response variables that vary between 0 and $100 \%$. Hence, we used beta regression mixed models with logit link since they provide predictions and confidence intervals limited to a range of $>0$ and $<$ 100 (Cribari-Neto and Zeileis 2010). When measurements included $0 \%$ or $100 \%$, we transformed observations by either adding or subtracting a small constant $x=0.0000001$ (Cribari-Neto and Zeileis 2010).

The models for testing the effect of dark incubation on the sporulating leaf area (\%) and the chlorotic leaf area (\%) included the fixed effect incubation type (24 h-dark and $12 \mathrm{~h}-\mathrm{d} / \mathrm{n})$ and the random effect leaf $(1-4)$ was nested 
in plant ID (1-10), plant ID was nested within run of the experiment $(1,2)$. The random effect accounts for the hierarchy in design, i.e. the four measurements per plant and the three runs of the experiment. Similar models were fitted for testing the effect of leaf wetness duration $(0 \mathrm{~h}$, $3 \mathrm{~h}, 6 \mathrm{~h}, 12 \mathrm{~h}, 24 \mathrm{~h}, 48 \mathrm{~h}, 5$ days to 7 days) on sporulating leaf area $(\%)$ chlorotic for the treatment of high humidity $(100 \%)$ at the end of the infection cycle. The observations of the treatment with low humidity $(60 \%)$ at the end of the infection cycle were not included into the statistical analysis since only 2 out of 336 cases showed sporulation.

To describe the temperature response curve and find the optimum temperature for conidia germination in vitro, summary statistics on minimum, median and maximum of observed values are graphically displayed for each experiment. To evaluate the effect of incubation temperature at different time steps after inoculation on disease development (sporulating leaf area (\%)) in vivo, a beta regression mixed effect model was fitted with the fixed effects incubation temperature $(10,15,20$ and $\left.25^{\circ} \mathrm{C}\right)$ and days post inoculation $(8,9,10$ and $14 \mathrm{dpi})$ and its two-way interaction. Random effect was leaf (14) nested in plant ID (1-16/1-8) nested in treatment (temperature) nested in run of the experiment (1-3).

The significance of fixed effects was tested by likelihood-ratio chi-square test. Tukey tests were employed for multiple comparisons of estimated

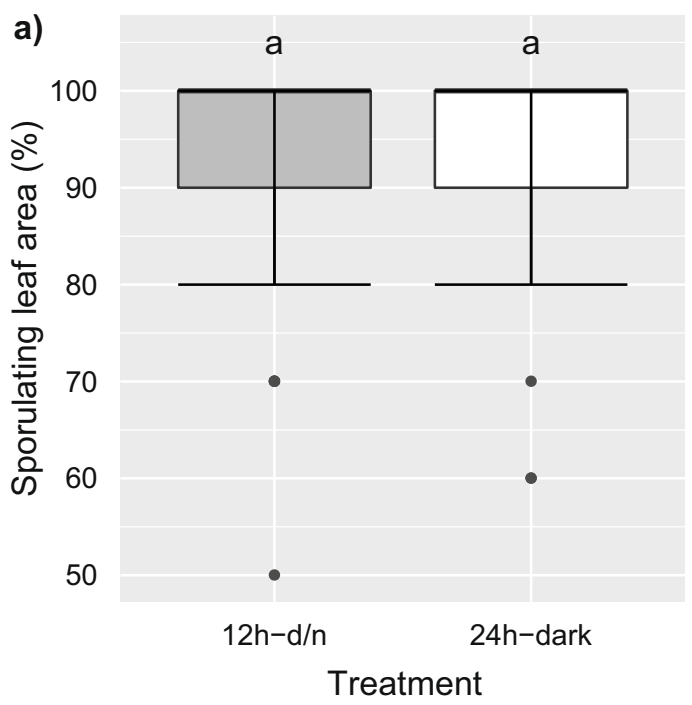

Fig. 2 Effect of $24 \mathrm{~h}$ dark incubation (24 h-dark) compared to incubation in a $12 \mathrm{~h}$ day-night rhythm $(12 \mathrm{~h}-\mathrm{d} / \mathrm{n})$ on disease development. Disease development was assessed by measuring marginal means using the emmeans package $(P<0.05)$. Residuals were plotted against fitted values and visually checked for patterns in all models and no abnormalities were observed.

\section{Results}

The effect of dark incubation and relative humidity on disease development in vivo

Both sporulating leaf area $(p=0.503$; estimated mean $24 \mathrm{~h}$-dark $=95.4 \%$; estimated mean $12 \mathrm{~h}-\mathrm{d} / n=94.9 \%$ ) and chlorotic leaf area $(p=0.644$; estimated mean $24 \mathrm{~h}$ dark $=6.0 \%$; estimated mean $12 \mathrm{~h}-\mathrm{d} / n=5.2 \%$ ) did not differ significantly between the two treatments, $24 \mathrm{~h}$ dark and $12 \mathrm{~h}-\mathrm{d} / \mathrm{n}$ (Fig. 2). For sporulating leaf area the medians and the upper quartile of both treatments were $100 \%$. For chlorotic leaf area the medians of both treatments were similar with $5 \%$ for the $24 \mathrm{~h}$-dark and $0 \%$ for $12 \mathrm{~h}-\mathrm{d} / \mathrm{n}$ treatment. The lower quartile was $0 \%$ for the chlorotic leaf area of both treatments. At the incubation temperature of $15{ }^{\circ} \mathrm{C}$ chlorotic leaf spots developed earliest at 6 to $7 \mathrm{dpi}$. Thus, only relatively little chlorotic leaf area was observed at the time of observation in comparison to sporulating leaf area.

In vitro pre-trials on $1.5 \%$ water agar, with an incubation at $15{ }^{\circ} \mathrm{C}$ and in darkness, showed that

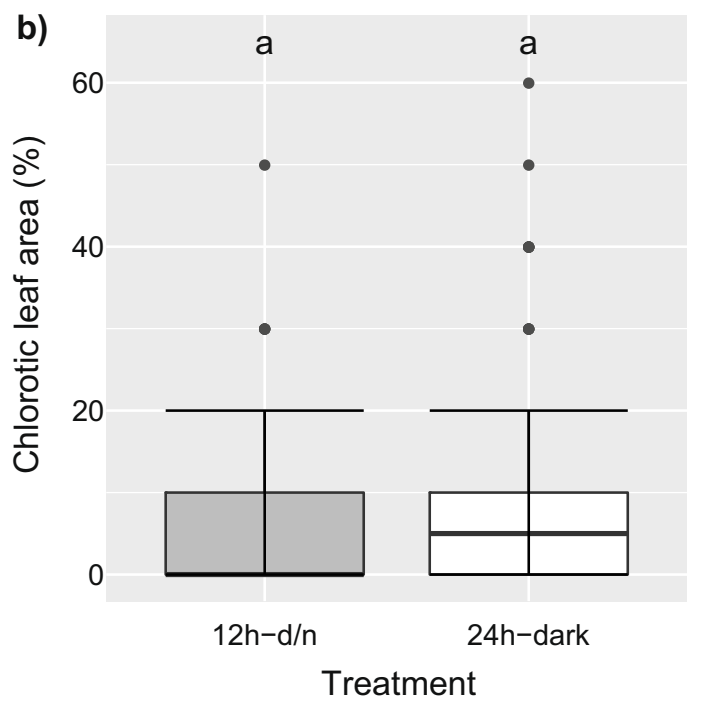

a) sporulating leaf area and b) chlorotic leaf area of $P$. salviaeofficinalis infecting Salvia officinalis. Groups with a common letter are not significantly different at $\mathrm{p}=0.05$ 

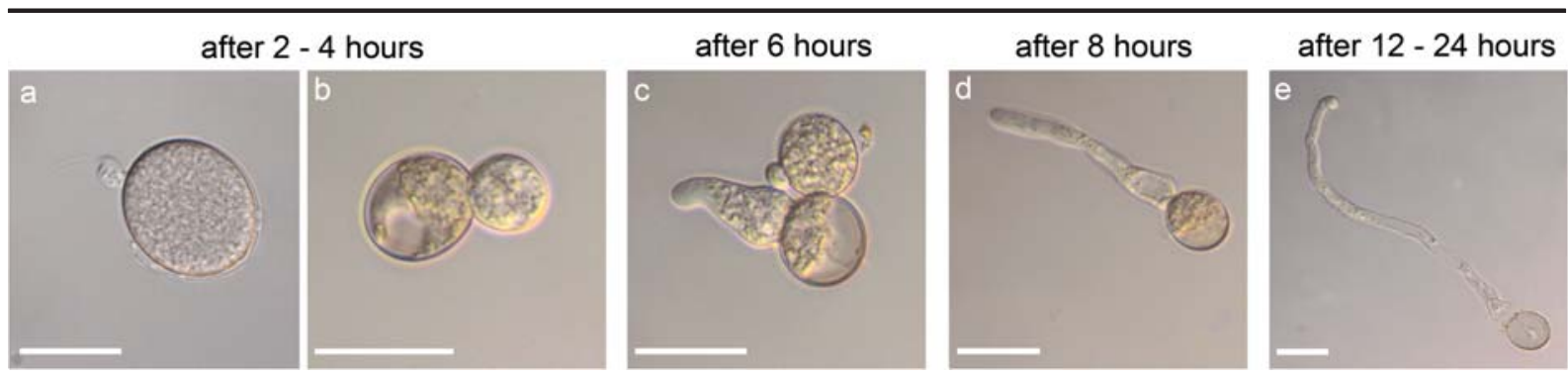

Fig. 3 Germinating conidia of $P$. salviae-officinalis on $1.5 \%$ water agar at different incubation times, incubated at $15^{\circ} \mathrm{C}$ and darkness. $\mathrm{a}, \mathrm{b}$ : Conidia with a germ-tube primordium; c: Germ-tube

germination started at 2 hpi (hours post inoculation) with the formation of a single, small, blister-like germtube primordium (Fig. 3). Six hours after inoculation, the germ-tube primordia started to stretch. Extended germ-tubes were observed 8 hpi. The germ-tubes ceased growth 12 to $24 \mathrm{hpi}$.

Only two out of 336 observations (one each in the $48 \mathrm{~h}$ and $5 \mathrm{~d}$ treatment) showed sporulation at low humidity at the end of the infection cycle (Fig. 4a). In contrast, in the treatment of high humidity at the end of the infection cycle, sporulating leaf area increased with increasing leaf wetness duration (Fig. 4b). Sporulation was already induced when plants were incubated at $100 \%$ rh.

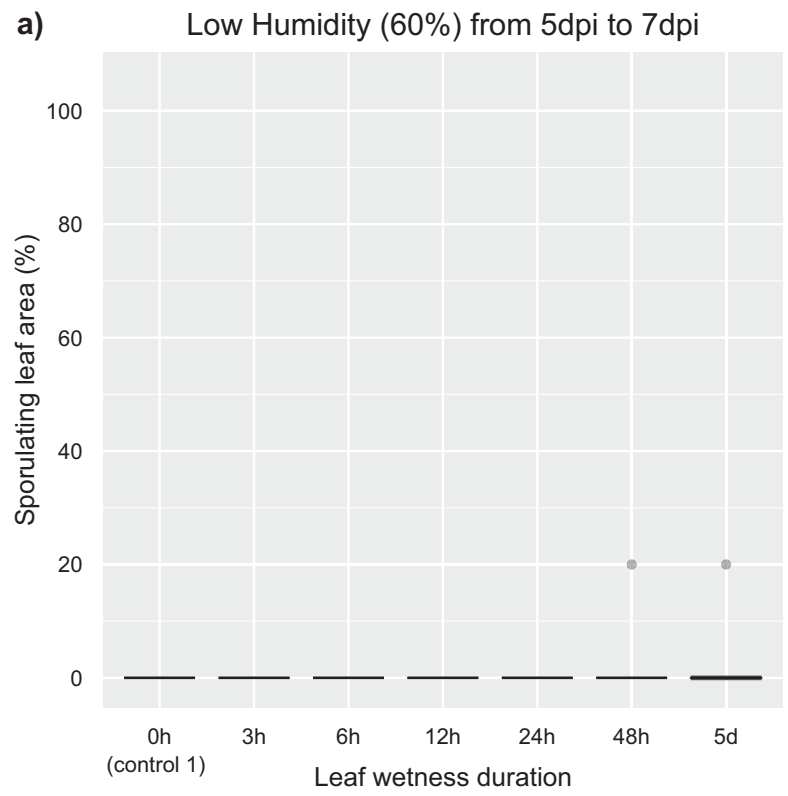

Fig. 4 Effect of leaf wetness duration after inoculation and humidity at the end of the infection cycle on disease development. Control 1 and control 2 refer to control 1 and control 2 described in the test scheme of Fig.1. Only for those treatments marked with primordia start to stretch; d: Conidia with young germ-tube; e: Conidia after $24 \mathrm{~h}$ with a fully elongated germ-tube. Scale: $25 \mu \mathrm{m}$

only for the first $3 \mathrm{~h}$ after the inoculation. Sporulating leaf area was lower in treatments with $3 \mathrm{~h}$ (median 10\%) than in treatments with $6 \mathrm{~h}$ (median $60 \%$ ) and longer leaf wetness duration (median $\geq$ $70 \%$ for $12 \mathrm{~h}, 24 \mathrm{~h}, 48 \mathrm{~h}$ and $7 \mathrm{~d}$ ).

The effect of temperature on conidia germination in vitro and disease development in vivo

Peronospora salviae-officinalis did germinate in vitro over a temperature range between 2 and $30^{\circ} \mathrm{C}$. The temperature response pattern was similar across the three replicates/experiments but much lower germination rates were observed in experiment 1 compared to

b) High Humidity (100\%) from $5 \mathrm{dpi}$ to $7 \mathrm{dpi}$

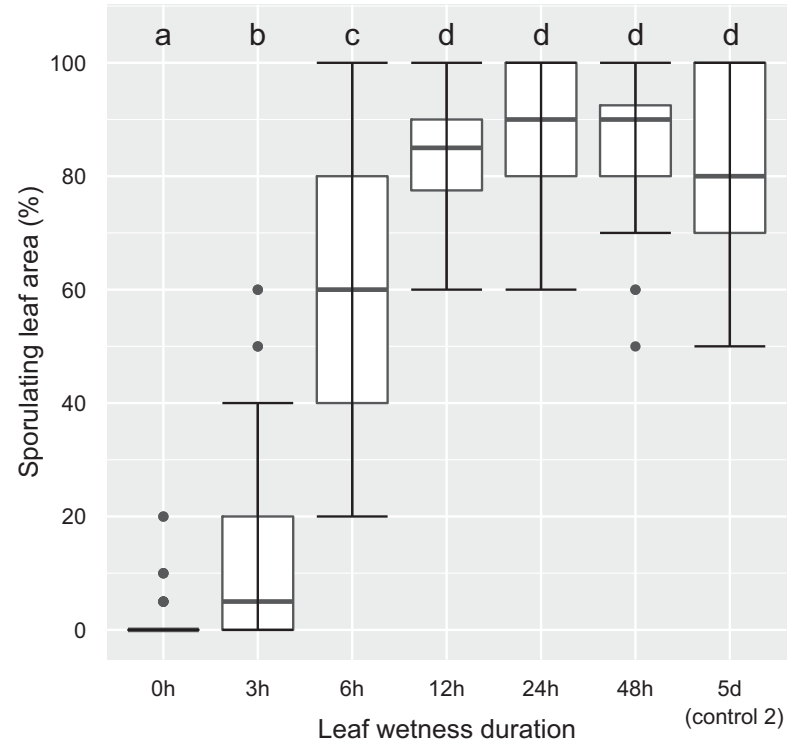

letters a mixed effect model was fitted. The treatments at low humidity (a) were not statistically analyzed because (almost) no sporulation was observed. Groups with different letters indicate significant differences in means at alpha 0.05 
experiments 2 and 3 . The optimum temperature for conidial germination in vitro was $20{ }^{\circ} \mathrm{C}$ in all three experiments (Fig. 5). At $20{ }^{\circ} \mathrm{C}, 82$ out of 100 conidia germinated in the first $24 \mathrm{~h}$ in experiment 2 and 3 and 43 out of 100 in experiment 1 . The majority, i.e. more than $90 \%$ of conidia, germinated in the first $24 \mathrm{~h}$ in experiment 2 and 3 (Fig. 5).

The highest sporulating leaf area in vivo was observed at inoculation temperatures at 20 degrees after 7 dpi (median at $80 \%$ ), and at $15{ }^{\circ} \mathrm{C}$ after 9 dpi (median at $80 \%$ ) (Fig. 6). At temperatures of 10 and $15{ }^{\circ} \mathrm{C}$ sporulation started at 8 dpi or 5 to $6 \mathrm{dpi}$, respectively, while at temperatures of 20 and $25^{\circ} \mathrm{C}$ it started earlier at 4 dpi. At $5{ }^{\circ} \mathrm{C}$ P. salviae-officinalis did not sporulate until $14 \mathrm{dpi}$, but when plants were incubated at $25^{\circ} \mathrm{C}$ for further three days, sporulation was observed (see 17 dpi in Fig. 6). The mixed model indicated a significant interaction between incubation temperature and time after inoculation on sporulating leaf area (all $p$-values $<0.001$ ), which showed an increase in sporulating leaf area at $10{ }^{\circ} \mathrm{C}$ with increasing dpi, while at 15,20 and $25^{\circ} \mathrm{C}$ sporulating leaf area was already at high and constant level. This pattern was constant across all three experiments (Fig. S1).
High temperatures expedite the appearance of symptomatic spots and hence increase symptomatic leaf area (Fig. S2). The highest symptomatic leaf area was observed at inoculation temperatures at $20{ }^{\circ} \mathrm{C}$ after 9 dpi (median at $80 \%$ ), and at $15^{\circ} \mathrm{C}$ as well as $25^{\circ} \mathrm{C}$ after 8 to $9 \mathrm{dpi}$ (median at $70 \%$ ). At 20 and $25^{\circ} \mathrm{C}$ first symptoms became visible at 5 dpi, at $15{ }^{\circ} \mathrm{C}$ at $6 \mathrm{dpi}$ and at $10{ }^{\circ} \mathrm{C}$ at $10 \mathrm{dpi}$. At $5{ }^{\circ} \mathrm{C}$ no symptomatic leaf area was observed during the experiments. The mixed model indicated a significant interaction between incubation temperature and time after inoculation on symptomatic leaf area (all $p$-values <0.001), which showed an increase in symptomatic leaf area with increasing dpi, which differed in strength and maximum between temperatures (see suppl. Fig. S2). This pattern was constant across all three experiments (see suppl. Fig. S3).

In this study oospores of $P$. salviae-officinalis were observed in infected sage leaves after incubation at temperatures between 15 and $25{ }^{\circ} \mathrm{C}$ (Fig. 7). They were round and thick-walled, sometimes surrounded by a hyaline oogonium, and were formed close to the cuticle. The diameter of
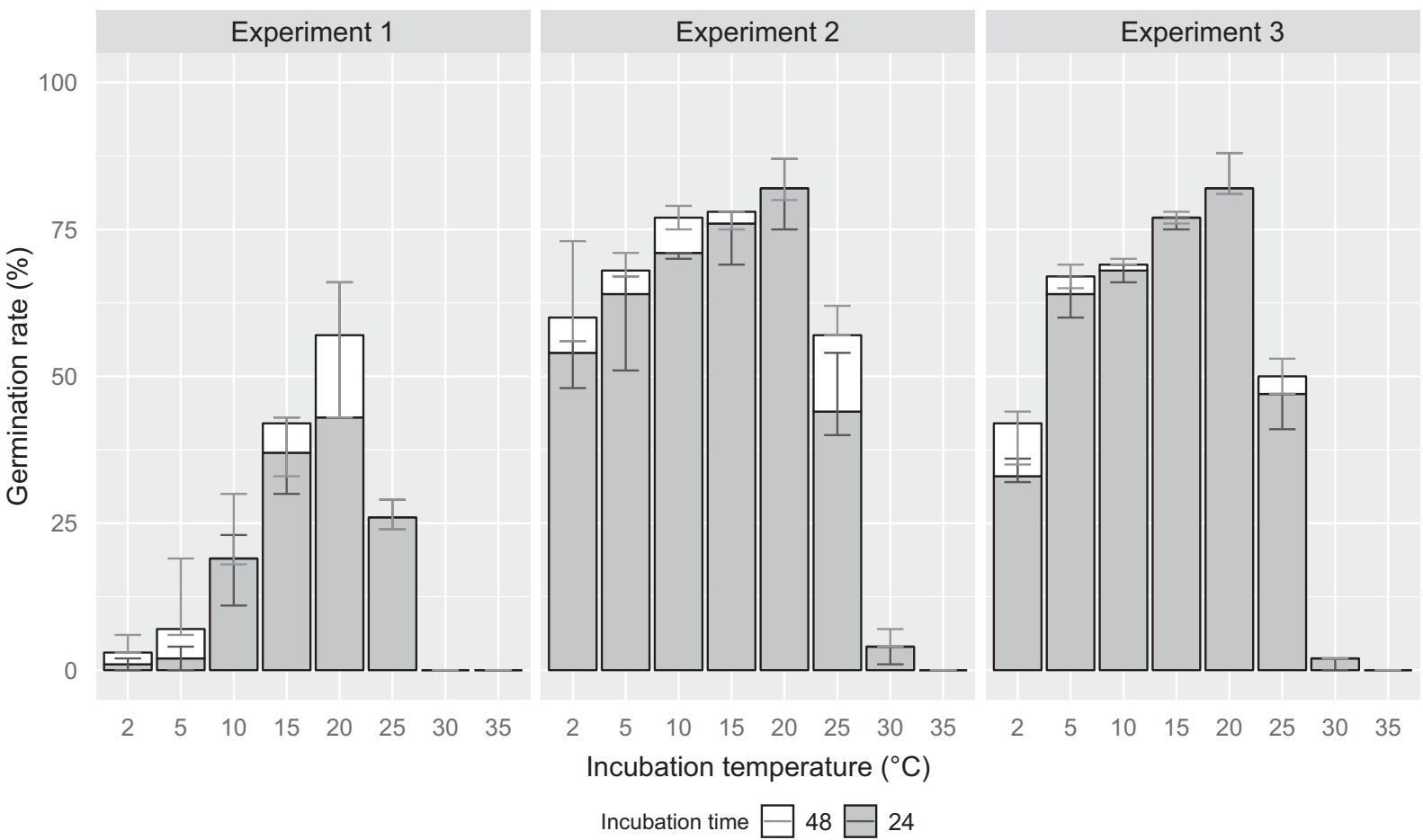

Fig. 5 Conidial germination rate (\%) of Peronospora salviaeofficinalis in vitro, incubated under different temperatures observed after $24 \mathrm{~h}$ (grey bars) and $48 \mathrm{~h}$ (white bars) in three replicated experiments. Barplots indicate the median and error bars the minimum and maximum germination rate 


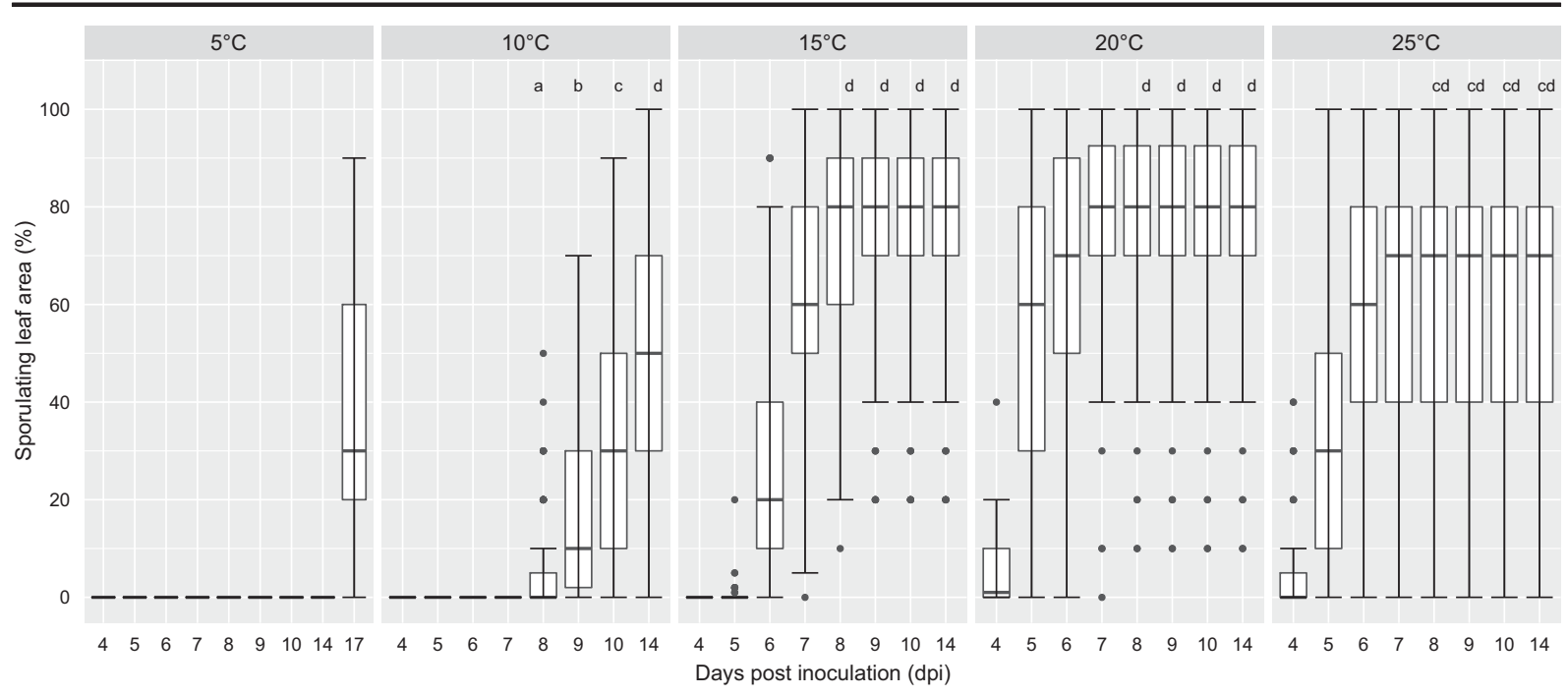

Fig. 6 Sporulating leaf area (\%) of Peronospora salviaeofficinalis on Salvia officinalis at different incubation temperatures and days post inoculation. A mixed effect model was fitted for treatments $10-25^{\circ} \mathrm{C}$ for $8-14$ dpi. Different letters indicate significant differences between the treatments according to Tukey post hoc test at significance level 0.05 . The $5{ }^{\circ} \mathrm{C}$-treatment was not

oospores of P. salviae-officinalis was between 26 and $41 \mu \mathrm{m}$. At 20 and $25^{\circ} \mathrm{C}$ incubation temperature oospores developed at $8 \mathrm{dpi}$, at $15{ }^{\circ} \mathrm{C}$ at $14 \mathrm{dpi}$. No oospores were found in infected leaves of the 5 and $10{ }^{\circ} \mathrm{C}$ treatments during the time of observation.

\section{Seed testing for P. salviae-officinalis}

All eight seed samples from $S$. officinalis tested carried DNA of oomycetes as revealed by PCR specific for the ITS-region of oomycetes (Fig. 8). The positive control included in the mixed effect model because no sporulation was observed during the whole 14 days of the experiment. Note: Level $17 \mathrm{dpi}$ at temperature $5{ }^{\circ} \mathrm{C}$ represents the sporulating leaf area (\%) after an increase in incubation temperature from 5 to $25^{\circ} \mathrm{C}$ for three days after the end of the experiment

for P. salviae-officinalis showed a clear and strong band around $1250 \mathrm{bp}$. Amplification products of samples $1.1-2.3,3.3,4.1,4.3,5.1,5.2,6.2,7.1,7.2,8.1-8.2$ were of the same size as the positive control and were sequenced for verification. BLASTn results of the obtained sequences in GenBank gave best hits with P. salviae-officinalis $(1.1,1.2,2.1-2.3,3.3,4.1,4.3$, 5.1, 6.2, 7.1, 7.2, 8.1, 8.3) and Pythium spp. (1.3, 5.2 and 8.2 ), respectively. The 14 sequences, which gave best hits with $P$. salviae-officinalis were all identical among each other and clustered without any genetic
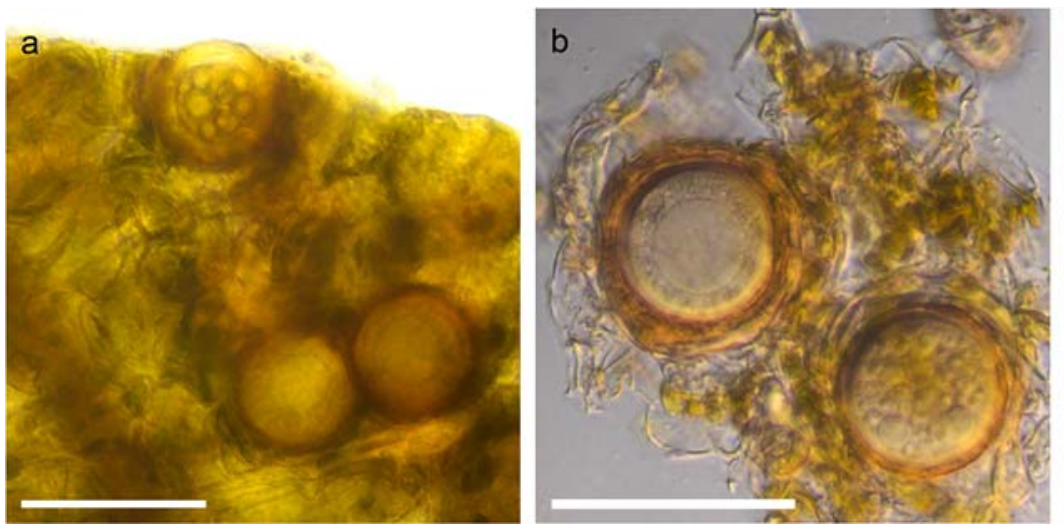

Fig. 7 Oospores of Peronospora salviae-officinalis in infected leaf material of Salvia officinalis 14 days after inoculation and incubation at $15^{\circ} \mathrm{C}$. a: Section through an infected leaf reveals oospores between leaf mesophyll cells. b and c: Squeeze preparation of necrotic leaf spots of sage leaves showing oospores of P. salviae-officinalis. Scale: $50 \mu \mathrm{m}$ 


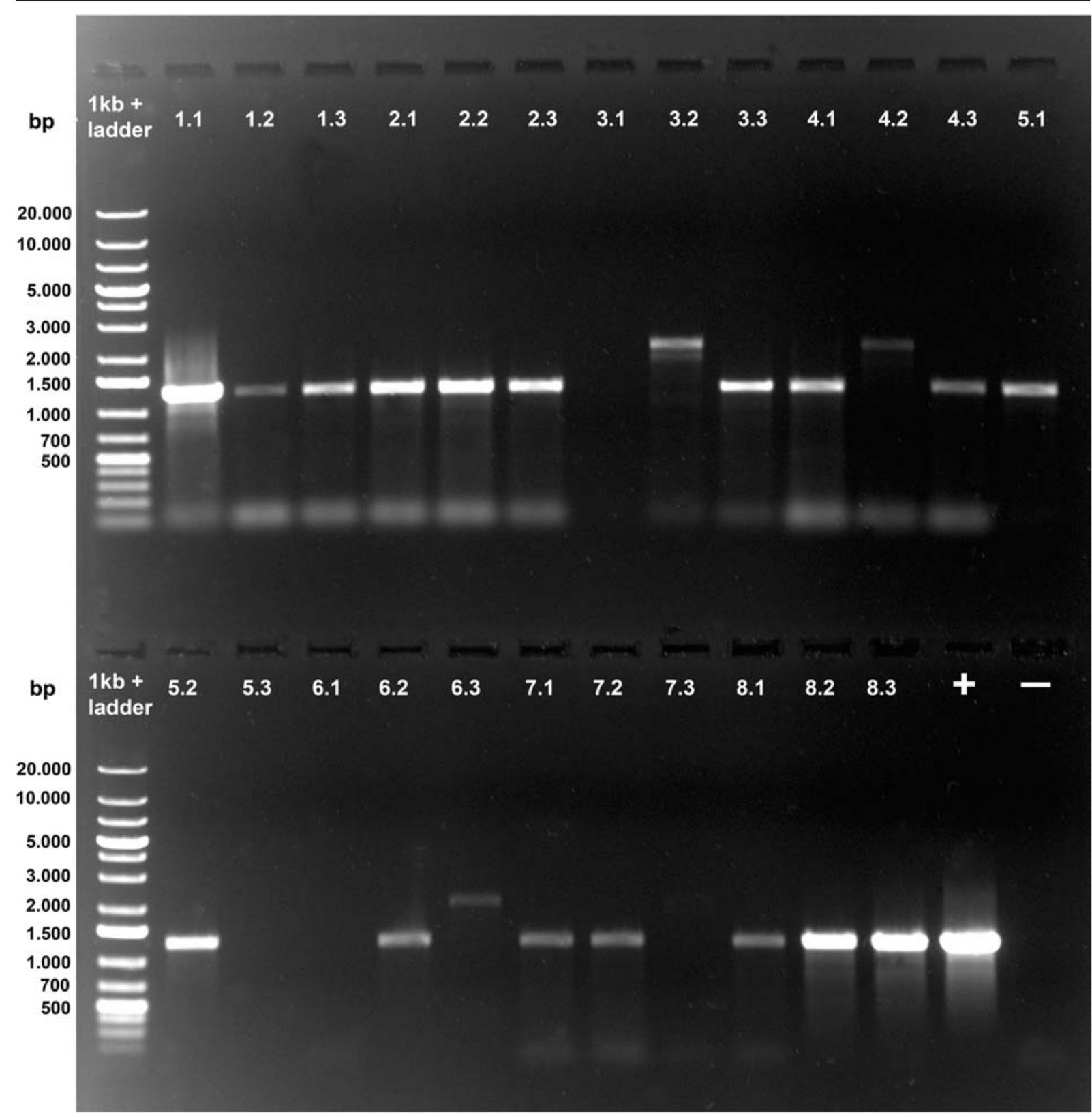

Fig. 8 Picture of an agarose gel of PCR products of the ITS rDNA of oomycetes extracted from seeds of Salvia officinalis. Fragment sizes are indicated to the left. DNA of Peronospora salviae-

distance together with P. salviae-officinalis, but also with $P$. belbahrii, in the phylogeny comprising a larger taxon sampling of Peronospora and Pythium species (Fig. 9). If only P. belbahrii and P. salviae-officinalis were used in a neighbour joining analysis (Fig. 10) they clearly clustered in two individual groups, which resulted from 2 to 3 distinct substitutions. The small genetic distances caused by the substitutions were blurred in the officinalis was used as positive control (+), a PCR mix without added DNA as negative control (-)

larger data set because they were positioned at gap positions in the alignment that were introduced due to the larger and phylogenetically heterogenous taxon sampling. The sequences obtained from seed samples $1.3,5.2$ and 8.2 differed slightly (1.3 and 8.2) or significantly (5.2 from 1.3 and 8.2) among each other and clustered with different Pythium lineages, accordingly. The DNA sequence obtained from seed sample 5.2 


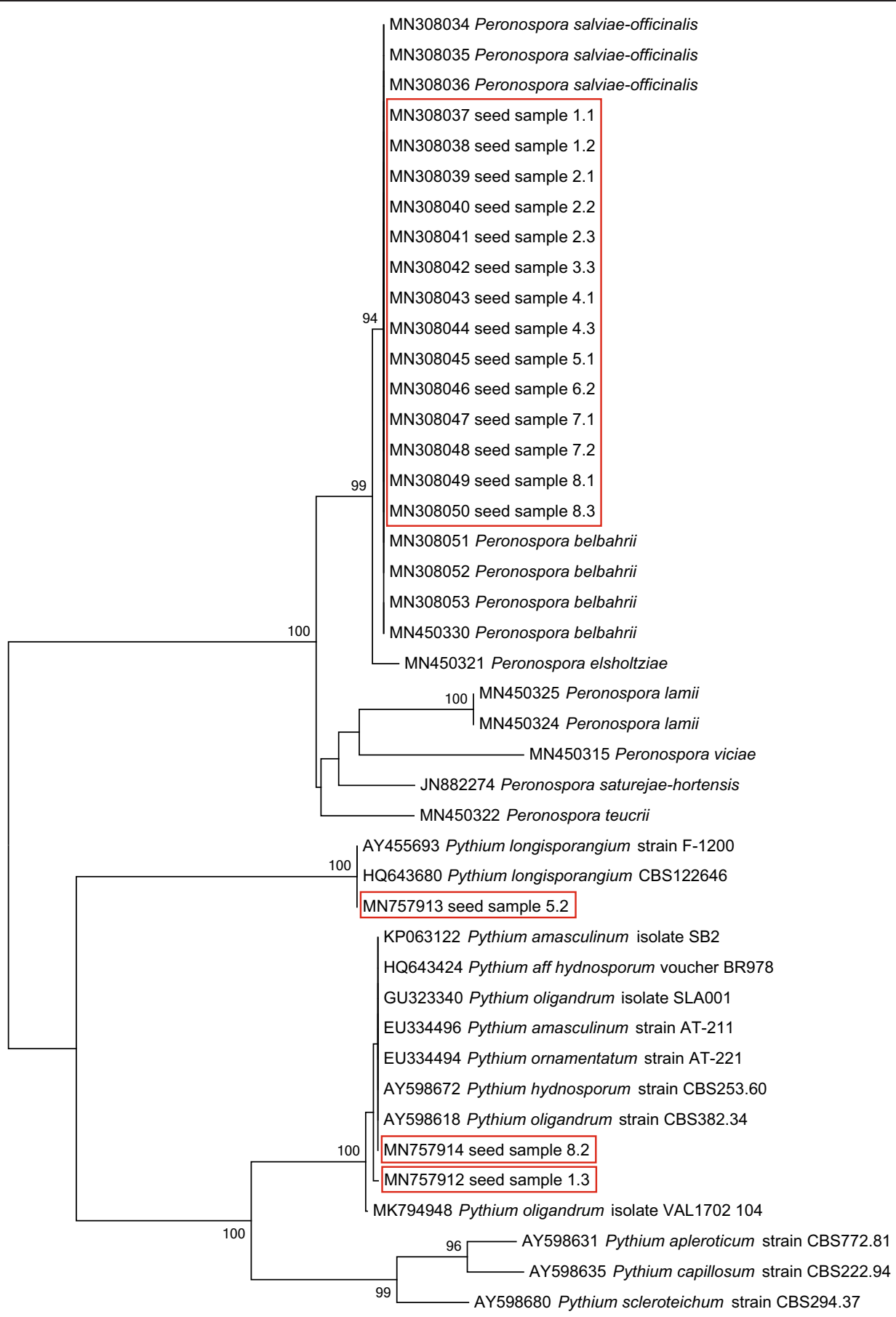

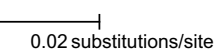

Fig. 9 Phylogenetic placement of the sequences obtained from sage seed samples (highlighted by a red box) based on ITS rDNA sequences using Neighbour Joining analysis with Kimura-2parameter model within representative samples of Peronospora and Pythium species. Bootstrap values greater than $70 \%$ are given above the branches. The number of nucleotide changes between taxa is represented by branch length and the scale bar represents the number of nucleotide substitutions per site. Peronospora samples acquired from seeds of Salvia officinalis cluster with sequences of $P$. salviae-officinalis and $P$. belbahrii. Scale bar indicates number of substitutions per site 


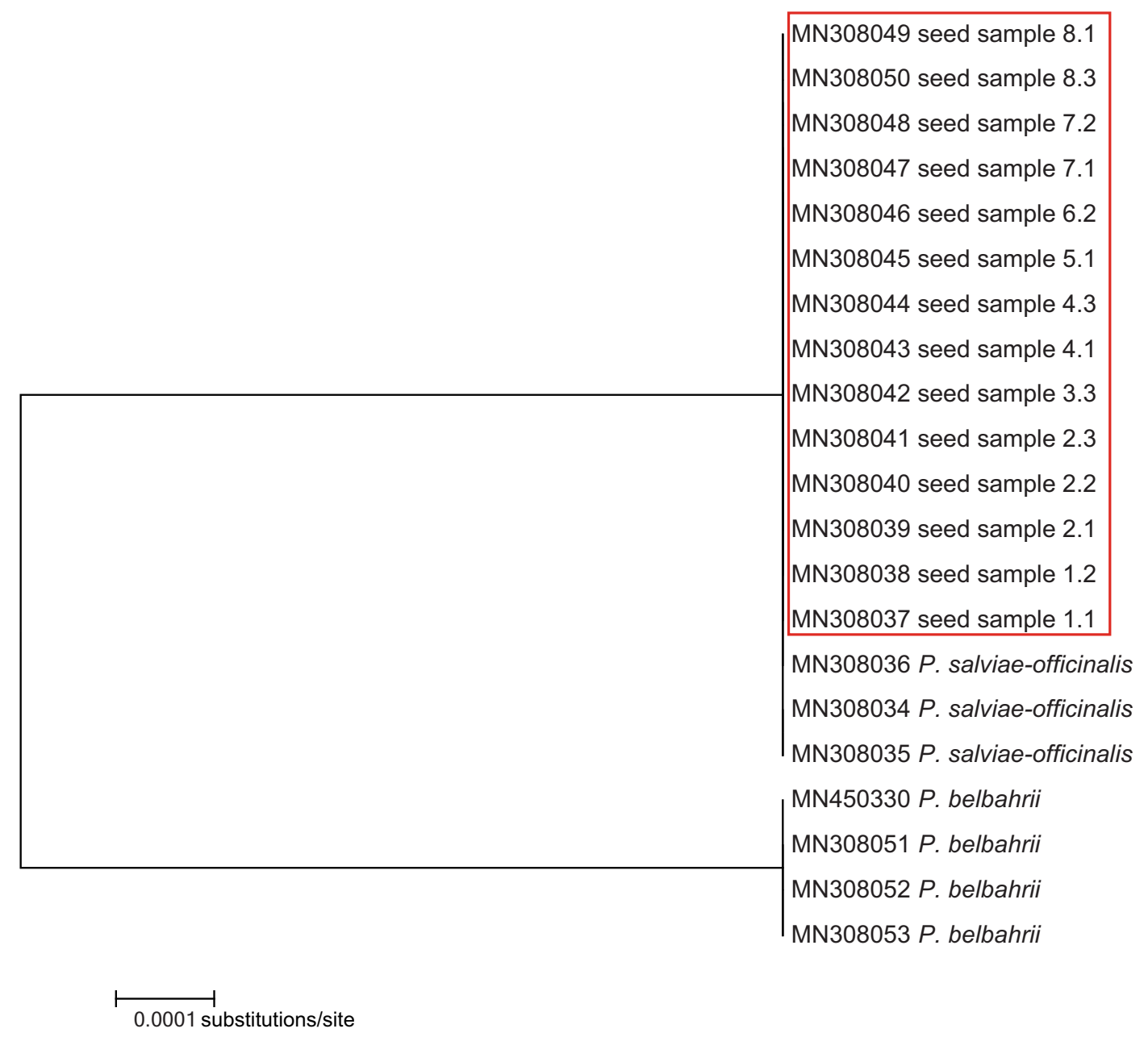

Fig. 10 Neighbour joining analysis of sequences from seeds tested positive for Peronospora (highlighted by red box) with ITS rDNA sequences of $P$. salviae-officinalis and $P$. belbahrii, respectively. Scale bar represents nucleotide substitutions per site.

clustered without any genetic distance together with Pythium longisporangium specimens, suggesting conspecificity. The sequences of the Pythium spp. found in seed samples 1.3 and 8.2 differed slightly among each other and could not be resolved based on ITS clustering within a heterogenous group consisting of sequences of P. oligandrum, P. hydnosporum, $P$. ornamentum, $P$. amasculinum. The final alignments obtained were deposited in TreeBASE and are available under http://purl. org/phylo/treebase/phylows/study/TB2:S25456.

Microscopy of the filter papers obtained by the spore filtration method of the eight seed samples showed oospore-like structures on the membrane filter (Fig. 11), which were confirmed as oospores when observed in higher magnification in lactic acid. Shape
All Peronospora sequences obtained from seeds of Salvia officinalis cluster with $P$. salviae-officinalis and can be distinguished from the closely related $P$. belbahrii. Scale bar indicates number of substitutions per site

and size of these oospores were consistent with shape and size of oospores found in leaves of $S$. officinalis infected with $P$. salviae-officinalis. The oogonium, was not detectable, and might have been disrupted during the seed washing process. Besides oospores, conidia and conidiophores that were characteristic of $P$. salviaeofficinalis were detected on the membrane filters of two seed lots out of eight.

\section{Discussion}

Peronospora salviae-officinalis, the downy mildew of common sage, is now widespread and impedes sage production worldwide while basic knowledge on the 

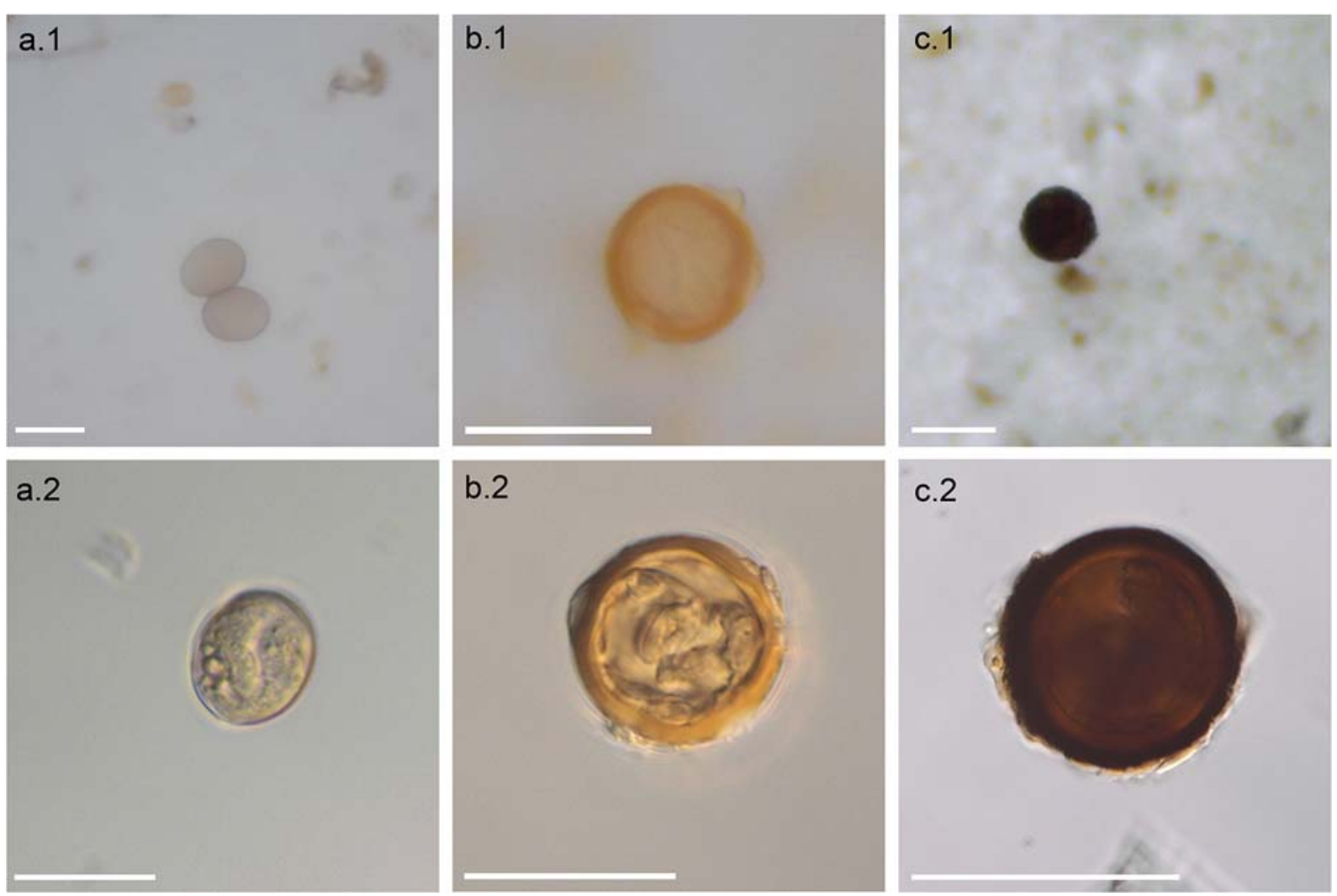

Fig. 11 Oospores and conidia collected from sage seeds by seed washing. a.1-c.1: Pictures of conidia and oospores on membrane filters after seed washing. a.2-c.2: Conidia and oospores after

epidemiology of the disease was scarce so far. In the present study we determined the impact of basic epidemiological factors such as temperature and moisture on speed and intensity of disease development to improve our understanding of the infection process. We also screened for oospores in planta and in seed lots to gain insights into the potential avenues of spread of the disease that eventually could result in better containment of the disease.

Dark incubation over a prolonged time was not necessary for successful artificial inoculation and infection of sage downy mildew. In infection trials, downy mildews are usually incubated in complete darkness for the first $24 \mathrm{~h}$ (Diez-Navajas et al. 2008; Lebeda and Cohen 2010; Neufeld and Ojiambo 2012; Djalali FarahaniKofoet et al. 2014; Kandel et al. 2019). Our findings suggest that the common practice of keeping downy mildews for $24 \mathrm{~h}$ in dark after inoculation is not essential for the infection success. We also found that leaf wetness for three hours after inoculation is sufficient for infection. Similar times had been determined for other transfer to $60 \%$ lactic acid on an objective microscope slide. a.1 and 2: conidia. b.1, c.1, b.2 and c.2: Oospores. Scales: a.1 and 2: $20 \mu \mathrm{m}, \mathrm{b} .1$ and 2: $25 \mu \mathrm{m}, \mathrm{c} .1$ and 2: $50 \mu \mathrm{m}$

downy mildews such as Pseudoperonospora cubensis (Cohen 1977; Neufeld and Ojiambo 2012), Plasmopara viticola (Gäumann 1951a), and P. belbahrii (Cohen and Ben-Naim 2016). For sporulation, however, a second event of high humidity or leaf wetness, is necessary, which is probably the case for all downy mildew species (Gäumann 1951b; Lange et al. 1989; Garibaldi et al. 2007). The timing of this second humidity event depends on incubation temperature. At $10{ }^{\circ} \mathrm{C}$ a humidity event no earlier than eight to ten days post inoculation will lead to sporulation, while at $25{ }^{\circ} \mathrm{C}$ high humidity between four to six dpi is a sufficient time span. These results are in line with observations made on cucumber downy mildew requiring an initial minimum duration of leaf wetness of two hours for successful infection (Cohen 1977), and later a minimum of at least $90 \%$ rel. humidity for sporangiophores production (Palti and Cohen 1980; Lebeda and Cohen 2010). In our studies temperatures between 15 and $20{ }^{\circ} \mathrm{C}$ were most favourable for disease progress, resulting in the highest sporulating and symptomatic leaf area. Similar 
temperature ranges were also found favourable for the infection of $P$. belbahrii on basil (Djalali FarahaniKofoet et al. 2014) and the cucurbit downy mildew PS. cubensis (Neufeld and Ojiambo 2012). While leaf wetness is essential for infection and sporulation, temperature seems to be an important driver for the extent of disease development with highest disease outcomes at temperatures between 20 and $25^{\circ} \mathrm{C}$. Nevertheless, conidia of $P$. salviae-officinalis were able to infect sage plants at all temperatures tested between 5 and $25^{\circ} \mathrm{C}$. Even at $5{ }^{\circ} \mathrm{C} \mathrm{P}$. salviae-officinalis was still able to infect plants, but only sporulated at higher temperatures of at least $10{ }^{\circ} \mathrm{C}$. This implies that $P$. salviae-officinalis can latently infect sage during long periods of the year in many climatic regions and is then able to sporulate quickly if temperatures rise.

In the present study oospores readily developed within $8 \mathrm{dpi}$ at temperatures between 20 and $25^{\circ} \mathrm{C}$ and 14 dpi at $15^{\circ} \mathrm{C}$. Montes-Borrego et al. (2009) demonstrated that oospores of opium poppy downy mildew in infested soil or leaf debris are an effective inoculum for early infections of poppy seedlings through plant roots. As oospores were observed frequently at higher temperatures in infected sage plants in our infection trials particular caution is recommended concerning crop residues from infected stands. As infected leaf debris decomposes and oospores are released, inoculum in soil may accumulate over the years if infested plants are not effectively removed from the field.

Contamination of sage seeds with $P$. salviaeofficinalis were found in all seed lots investigated based on ITS-PCR and sequencing. Less frequently seed contamination with presumably Pythium longisporangium and one or two other Pythium species were detected. By applying a spore filtration technique to sage seeds the presence of oospores and conidia in seed samples could also be proven microscopically. However, it is difficult to distinguish between oospores of Peronospora and Pythium based on microscopy only. Oospores sticking on to seeds of their host plants are very efficiently spread into new areas (Rennie and Cockerell 2006). This was shown for example for $P$. belbahrii (Farahani-Kofoet et al. 2012; Garibaldi et al. 2004), P. effusa (Kunjeti et al. 2016) and $P$. arborescens (Landa et al. 2007). The frequent contaminations of sage seed lots with P. salviae-officinalis found by us could explain the quick worldwide spread of the disease as well as the observations from a monitoring survey conducted in 2016 and 2017 where $P$. salviae-officinalis was detected in all eight sage stands investigated throughout Germany, even in newly sown stands (Thiemann and Blum 2019). Taken together, the reported findings on the epidemiology and infection biology of $P$. salviaeofficinalis could serve as basis for the development of forecast models for the occurrence of downy mildew in sage production. Furthermore, our results may help to develop appropriate combat and containment strategies against sage downy mildew and hence support sage cultivation worldwide.

Acknowledgments This study was supported by the Federal Ministry of Food and Agriculture by decision of the German Bundestag. The authors thank Petra Westphal for technical assistance. We extend our sincere thanks to Christoph Grunert, Jutta Gabler and Thomas Kühne for their great commitment in initiating this study, their ongoing interest and advice. Dorothea Lehmann of Bombastus Werke AG and her team for providing material and for help in sampling are gratefully acknowledged. We also thank Hanna Blum and Kim Thiemann from Ökoplant e.V. for providing additional samples from a German-wide monitoring of $P$. salviaeofficinalis as well as for sage seeds, and Roxana Djalali FarahaniKofoet from IPK Gatersleben for providing samples of Peronospora belbahrii.

Funding Information Open Access funding provided by Projekt DEAL.

Data availability The datasets generated during and/or analysed during the current study are available from the corresponding author on reasonable request.

\section{Compliance with ethical standards}

This article does not contain any studies with human or animal subjects performed by any of the authors.

Conflict of interest The authors declare that they have no conflict of interest.

Open Access This article is licensed under a Creative Commons Attribution 4.0 International License, which permits use, sharing, adaptation, distribution and reproduction in any medium or format, as long as you give appropriate credit to the original author(s) and the source, provide a link to the Creative Commons licence, and indicate if changes were made. The images or other third party material in this article are included in the article's Creative Commons licence, unless indicated otherwise in a credit line to the material. If material is not included in the article's Creative Commons licence and your intended use is not permitted by statutory regulation or exceeds the permitted use, you will need to obtain permission directly from the copyright holder. To view a copy of this licence, visit http://creativecommons.org/licenses/by/4.0/. 


\section{References}

Auguie, B. (2017). gridExtra: Miscellaneous functions for "Grid" graphics. $R$ package version 2.3 .

Bache, S. M. W. H. (2014). magrittr: A Forward-Pipe Operator for R. $R$ package version 1.5.

Belbahri, L., Calmin, G., Pawlowski, J., \& Lefort, F. (2005). Phylogenetic analysis and real time PCR detection of a presumbably undescribed Peronospora species on sweet basil and sage. Mycological Research, 109(Pt 11), 1276-1287. https://doi.org/10.1017/s0953756205003928.

Brooks, M. E., Kristensen, K., van Benthem, K. J., Magnusson, A., Berg, C. W., Nielsen, A., et al. (2017). glmmTMB balances speed and flexibility among packages for zero-inflated generalized linear mixed modeling. $R$ Journal, 9(2), 378400. https://doi.org/10.32614/Rj-2017-066.

Choi, Y. J., Shin, H. D., \& Thines, M. (2009). Two novel Peronospora species are associated with recent reports of downy mildew on sages. Mycological Research, 113(Pt 12), 1340-1350. https://doi.org/10.1016/j.mycres.2009.08.010.

Cohen, Y. (1977). The combined effects of temperature, leaf wetness, and inoculum concentration on infection of cucumbers with Pseudoperonospora cubensis. Canadian Journal of Botany, 55, 1478-1487.

Cohen, Y., \& Ben-Naim, Y. (2016). Nocturnal fanning suppresses downy mildew epidemics in sweet basil. PLoS One, 11(5), e0155330. https://doi.org/10.1371/journal.pone.0155330.

Cooke, D. E., Drenth, A., Duncan, J. M., Wagels, G., \& Brasier, C. M. (2000). A molecular phylogeny of Phytophthora and related oomycetes. Fungal Genetics and Biology, 30(1), 17-32. https://doi.org/10.1006/fgbi.2000.1202.

Cribari-Neto, F., \& Zeileis, A. (2010). Beta regression in R. Journal of Statistical Software, 34(2), 1-24. https://doi. org/10.18637/jss.v034.i02.

Diez-Navajas, A. M., Wiedemann-Merdinoglu, S., Greif, C., \& Merdinoglu, D. (2008). Nonhost versus host resistance to the grapevine downy mildew, Plasmopara viticola, studied at the tissue level. Phytopathology, 98(7), 776-780. https://doi. org/10.1094/PHYTO-98-7-0776.

Djalali Farahani-Kofoet, R., Römer, P., \& Grosch, R. (2014). Selecting basil genotypes with resistance against downy mildew. Scientia Horticulturae, 179, 248-255. https://doi. org/10.1016/j.scienta.2014.09.036.

Ellis, J. B., \& Kellerman, W. A. (1887). New Kansas Fungi. The Journal of Mycology, 3(9), 102-105.

Farahani-Kofoet, R. D., Romer, P., \& Grosch, R. (2012). Systemic spread of downy mildew in basil plants and detection of the pathogen in seed and plant samples. [short communication]. Mycological Progress, 11(4), 961-966. https://doi. org/10.1007/s11557-012-0816-z.

Felsenstein, J. (1985). Confidence-limits on phylogenies - an approach using the bootstrap. Evolution, 39(4), 783-791. https://doi.org/10.1111/j.1558-5646.1985.tb00420.x.

Fox, J. W. S. (2019). An R Companion to Applied Regression (3rd ed.). Thousand Oaks.

Gamliel, A., \& Yarden, O. (1998). Diversification of diseases affecting herb crops in Israel accompanies the increase in herb crop production. Phytoparasitica, 26(1), 53-58. https://doi.org/10.1007/Bf02981266.
Garibaldi, A., Minuto, G., Bertetti, D., \& Gullino, M. L. (2004). Seed transmission of Peronospora sp. of basil. Zeitschrift Fur Pflanzenkrankheiten Und Pflanzenschutz-Journal of Plant Diseases and Protection, 111(5), 465-469.

Garibaldi, A., Bertetti, D., \& Gullino, M. L. (2007). Effekt of leaf wetess duration and temperature on infection of downy mildew (Peronospora sp.) of basil. Journal of Plant Diseases and Protection, 114(1), 6-8.

Gäumann, E. (1923). Beiträge zu einer Monographie der Gattung Peronospora Corda (Vol. 5, Beiträge zur Kryptogamenflora der Schweiz ). Zürich.

Gäumann, E. (1951a). Die Infektion. In Pflanzliche Infektionslehre: Lehrbuch der Allgemeinen Pflanzenpathologie für Biologen, Landwirte, Förster und Pflanzenzüchter (Zweite, umgearbeitete Auflage ed.). Basel: Birkhäuser Verlag.

Gäumann, E. (1951b). Die Infektketten. In Pflanzliche Infektionslehre: Lehrbuch der Allgemeinen Pflanzenpathologie für Biologen, Landwirte, Förster und Pflanzenzüchter (Zweite, umgearbeitete Auflage ed.). Basel: Birkhäuser Verlag.

Hill, C. F., Pearson, H. G., \& Gill, G. S. C. (2004). Peronospora dianthi and Peronospora lamii, two downy mildews recently detected in New Zealand. 348.

Humphreys-Jones, D. R., Barnes, A. V., \& Lane, C. R. (2008). First report of the downy mildew Peronospora lamii on Salvia officinalis and Rosmarinus officinalis in the UK. Plant Pathology, 57(2), 372-372. https://doi.org/10.1111 j.1365-3059.2007.01654.x.

Kandel, S. L., Mou, B., Shishkoff, N., Shi, A., Subbarao, K. V., \& Klosterman, S. J. (2019). Spinach downy mildew: Advances in our understanding of the disease cycle and prospects for disease management. Plant Disease, 103(5), 791-803. https://doi.org/10.1094/PDIS-10-18-1720-FE.

Kassambara, A. (2019). ggpubr: 'ggplot2' Based Publication Ready Plots. $R$ package version 0.2.2.

Kietriber, M. (1984). Working sheet no. 53, Triticum aestivum, Tilletia controversa Kühn, Tilletia caries (DC) Tul., Tilletia foetida (Wallr.) Liro. In ISTA Handbook on Seed Health Testing. Zürich, Switzerland: International Seed Testing Association.

Kochman, J. M. T. (1970). Grzyby (Mycota); Glonowce (Phycomycetes), Wroslikowe (Peronosporales) (Flora Polska). Warsaw: Polska Akademia Nauk, Instytut Botaniki.

Kumar, S., Stecher, G., \& Tamura, K. (2016). MEGA7: Molecular Evolutionary Genetics Analysis Version 7.0 for Bigger Datasets. Molecular Biology and Evolution, 33(7), 18701874. https://doi.org/10.1093/molbev/msw054.

Kunjeti, S. G., Anchieta, A., Subbarao, K. V., Koike, S. T., \& Klosterman, S. J. (2016). Plasmolysis and vital staining reveal viable oospores of Peronospora effusa in spinach seed lots. Plant Disease, 100(1), 59-65. https://doi.org/10.1094 /PDIS-06-15-0672-RE.

Landa, B. B., Montes-Borrego, M., Munoz-Ledesma, F. J., \& Jimenez-Diaz, R. M. (2007). Phylogenetic analysis of downy mildew pathogens of opium poppy and PCR-based in Planta and seed detection of Peronospora arborescens. Phytopathology, 97(11), 1380-1390. https://doi.org/10.1094 /PHYTO-97-11-1380.

Lange, L., Eden, U., \& Olson, L. W. (1989). Zoosporogenesis in Pseudoperonospora cubensis, the causal agent of cucurbit 
downy mildew. Nordic Journal of Botany, 8(5), 497-504. https://doi.org/10.1111/j.1756-1051.1989.tb00527.x.

Lebeda, A., \& Cohen, Y. (2010). Cucurbit downy mildew (Pseudoperonospora cubensis) - Biology, ecology, epidemiology, host-pathogen interaction and control. European Journal of Plant Pathology, 129(2), 157-192. https://doi. org/10.1007/s10658-010-9658-1.

Lenth, R. (2019). Emmeans: Estimated marginal means, aka leastsquares means. $R$ package version 1.3.4.

Liberato, J. R., Forsberg, L., Grice, K. R., \& Shivas, R. G. (2006). Peronospora lamii on Lamiaceae in Australia. Australasian Plant Pathology, 35(3), 367-368. https://doi.org/10.1071 /Ap06027.

Longaray Delamare, A. P., Moschen-Pistorello, I. T., Artico, L., Atti-Serafini, L., \& Echeverrigaray, S. (2007). Antibacterial activity of the essential oils of Salvia officinalis L. and Salvia triloba L. cultivated in South Brazil. Food Chemistry, 100(2), 603-608. https://doi.org/10.1016/j.foodchem.2005.09.078.

McMillan, R. T. (1993). First report of downy mildew of Salvia in Florida. Plant Disease, 78, 317.

Mirjalili, M. H., Salehi, P., Sonboli, A., \& Vala, M. M. (2006). Essential oil variation of Salvia officinalis aerial parts during its phenological cycle. Chemistry of Natural Compounds, 42(1), 19-23.

Moncalvo, J. M., Wang, H. H., \& Hseu, R. S. (1995). Phylogenetic-relationships in Ganoderma inferred from the internal transcribed spacers and $25 \mathrm{~s}$ ribosomal DNA-sequences. Mycologia, 87(2), 223-238. https://doi. org/10.2307/3760908.

Montes-Borrego, M., Landa, B. B., Navas-Cortes, J. A., MunozLedesma, F. J., \& Jimenez-Diaz, R. M. (2009). Role of oospores as primary inoculum for epidemics of downy mildew caused by Peronospora arborescens in opium poppy crops in Spain. Plant Pathology, 58(6), 1092-1103. https://doi.org/10.1111/j.1365-3059.2009.02141.x.

Neufeld, K. N., \& Ojiambo, P. S. (2012). Interactive effects of temperature and leaf wetness duration on sporangia germination and infection of cucurbit hosts by Pseudoperonospora cubensis. Plant Disease, 96(3), 345-353. https://doi. org/10.1094/PDIS-07-11-0560.

Osipjan, L. L. (1967). Peronosporovye Griby (Mikoflora Armjanskoj SSR). Erevan: Erevanskij Gosudarstvennyj Universitet.

Palti, J., \& Cohen, Y. (1980). Downy mildew of cucurbits (Pseudoperonospora-Cubensis) - the fungus and its hosts, distribution, epidemiology and control. Phytoparasitica, 8(2), 109-147. https://doi.org/10.1007/Bf02994506.

Plenk, A. (2002). Peronospora lamii A. Braun, eine noch in Österreich seltene Krankheit an Salvia officinalis. Abstracts of ALVA Jahrestagung 2002, Klosterneuburg.
R Core Team (2018). R: A language and environment for statistical computing. R Foundation for statistical computing. In R. C. Team (Ed.). Vienna, Austria: R Foundation for Statistical Computing.

Raal, A., Orav, A., \& Arak, E. (2007). Composition of the essential oil of Salvia officinalis L. from various European countries. Natural Product Research, 21(5), 406-411. https://doi. org/10.1080/14786410500528478.

Rabenhorst, G. L. (1857). Klotzschii herbarium vivum mycologicum sistens fungorum per totam Germaniam crescentium collectionem perfectam.

Rennie, W. J., \& Cockerell, V. (2006). Seedborne diseases. In B. M. Cooke, D. G. Jones, \& B. Kaye (Eds.), The epidemiology of plant diseases (2nd ed., pp. 357-372). Dordrecht: Springer.

Saitou, N., \& Nei, M. (1987). The neighbor-joining method: A new method for reconstructing phylogenetic trees. Molecular Biology and Evolution, 4(4), 406-425. https://doi. org/10.1093/oxfordjournals.molbev.a040454.

Stanjavičenie, S. (1984). Peronosporovye griby Pribaltiki Vil'njus.

Sulniute, V., Baranauskiene, R., Ragazinskiene, O., \& Venskutonis, P. R. (2017). Comparison of composition of volatile compounds in ten Salvia species isolated by different methods. Flavour and Fragrance Journal, 32(4), 254-264. https://doi.org/10.1002/ffj.3389.

Tang, Y., Horikoshi, M., \& Li, W. X. (2016). Ggfortify: Unified Interface to visualize statistical results of popular R packages. R Journal, 8(2), 474-485.

Thiemann, K., \& Blum, H. (2019). Abschlussbericht Monitoring: Krankheiten und Schädlinge an Salbei (Salvia officinalis). https://oekoplant-ev.de/aktuelles.html. Accessed 15 Nov 2019.

Thines, M., Telle, S., Ploch, S., \& Runge, F. (2009). Identity of the downy mildew pathogens of basil, coleus, and sage with implications for quarantine measures. Mycological Research, 113(5), 532-540. https://doi.org/10.1016/j. mycres.2008.12.005.

USDA (1960). Index of plant diseases in the United States (Vol. No. 165, USDA agriculture handbooks). Washington, D. C.: U.S. Dept. of Agriculture.

Voglmayr, H., Montes-Borrego, M., \& Landa, B. B. (2014). Disentangling Peronospora on Papaver: Phylogenetics, taxonomy, nomenclature and host range of downy mildew of opium poppy (Papaver somniferum) and related species. PLoS One, 9(5), e96838. https://doi.org/10.1371/journal. pone. 0096838 .

Wickham, H. (2016). ggplot2: Elegant graphics for data analysis. New York: Springer-Verlag.

Wickham, H. F. R, Henry, L. and Müller, K. (2019). dplyr: A Grammar of Data Manipulation. $R$ package version 0.8.1. 